\title{
Performance of Rigid Steel Frames under Adequate Soil Conditions Using Seismic Code Provisions
}

\author{
Muhammad Tayyab Naqash, Qazi Umar Farooq \\ Department of Civil Engineering, Faculty of Engineering, Islamic University of Madinah, Medina, Kingdom of Saudi Arabia \\ Email: engr.tayyabnaqash@gmail.com, tayyab@iu.edu.sa, qaziumar@gmail.com,umar@iu.edu.sa
}

How to cite this paper: Naqash, M.T. and Farooq, Q.U. (2018) Performance of Rigid Steel Frames under Adequate Soil Conditions Using Seismic Code Provisions. Open Journal of Civil Engineering, 8, 91-101. https://doi.org/10.4236/ojce.2018.82008

Received: March 14, 2018

Accepted: May 8, 2018

Published: May 11, 2018

Copyright (c) 2018 by authors and Scientific Research Publishing Inc. This work is licensed under the Creative Commons Attribution International License (CC BY 4.0).

http://creativecommons.org/licenses/by/4.0/

\section{(c) (i) Open Access}

\begin{abstract}
This study is focused on nonlinear analysis and design of spatial and perimeter moment resisting frames for a 9-storeys office building having $9.15 \mathrm{~m}$ span. Seismic design criteria of Eurocode 8 Ductility Class High (DCH) with behavior factor (q) of 6.5 and AISC/ASCE code, Special Moment resisting Frame (SMF) with response modification factor $(\mathrm{R})$ of 8 were employed. The design outcomes are expressed in terms of frame performance (non-linear analysis), section profiles (code recommendations), strength-demand to capacity ratios, drift-demand to capacity ratios and structural weight. The consequences of the research compare two codes in term of weights and design performances. This will aid professional engineers and researchers to select effective design criteria and capacity design rules efficiently.
\end{abstract}

\section{Keywords}

Eurocodes, AISC, ASCE, FEMA, Moment Resisting Frames, Seismic

Resistance, Pushover Analysis

\section{Introduction}

Conventional structural design of buildings considers two limit states, the Ultimate Limit State (ULS) and the Serviceability Limit State (SLS). The ULS is used for strength criteria whereas SLS for deflection vibration and human factors. Furthermore, for structures vulnerable to strong or moderate seismic action, modern building codes [1] [2] [3] allow inelastic deformations but strictly limiting the development of unreliable mechanisms that could impair the global mechanisms of the structure. This all can be achieved through the smart use of capacity design approaches. For obtaining global ductility and better performance 
of a structural system, dissipative (structural fuses) and non-dissipative zones are defined by the codes. This obliged the structural design that non-dissipative zones should remain in the elastic field whereas the dissipative ones should undergo large inelastic deformations. To control such a global structural behavior, codes provide the so-called criterion of capacity design where non-dissipative members are designed for comparatively higher seismic forces than dissipative members and dissipative members are kept at such locations that will fail before the brittle members and subsequently will protect non-ductile elements by overstressing [4]. Many researches have been investigated these factors, such as Uang et al. [5]; who established $\mathrm{R}$ ( or $\mathrm{R}_{\mathrm{w}}$ ) and $\mathrm{C}_{\mathrm{d}}$ factors for building seismic provisions. Rahgozar and Humar [6], assessed the extent of reserve strength attributable to redistribution in steel frames. Bruneau et al. [7] and Mitchell et al. [8] included material effects caused by higher yield stress compared with the nominal value $R_{\text {yield }}$. In view of the above MRFs are designed in such a way that inelastic behavior is accommodated through plastic hinging within the spans of the beams rather than the columns, allowing the dissipation of energy in the beam ends and therefore the internal forces of columns members are increased by an over strength factor [4] [9]. The columns therefore behave elastically during a seismic event and allowed to carry the gravity loadings during a post seismic event [10].

\section{Design Case}

In order to investigate the design criteria of moment resisting frames according to the two codes the current study is conducted on 9 stories office building. The building has a rectangular plan measuring $54.9 \mathrm{~m}$ by $36.6 \mathrm{~m}$ in longitudinal and transversal direction, respectively. The typical floor plan of the building with the indication of spatial and perimeter frame is shown in Figure 1(a). The elevation of frame is given in Figure 1(b) where the outer columns are named as "coll" and the inner columns as " $c o h$ " and " $c o ß$ ". The columns are designed considering five blocks; the first block consists of single story whereas the rest of the

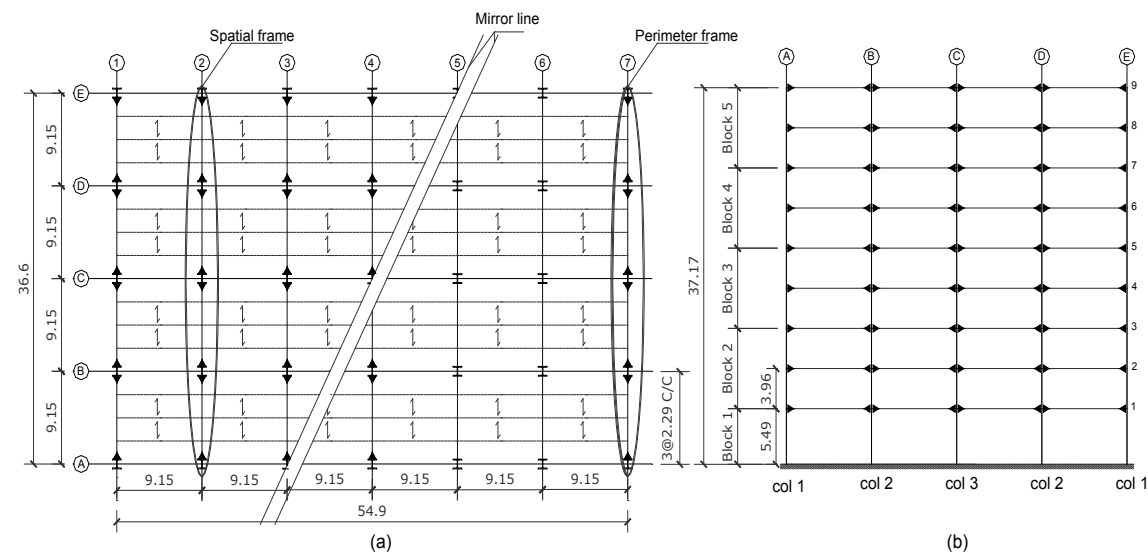

Figure 1. (a) Typical floor plan of the building and (b) Frame elevation. 
four blocks consist of 2 stories each. The inter story height of the base floor is $5.49 \mathrm{~m}$ whereas the other stories are $3.96 \mathrm{~m}$ in height giving rise to an overall height of $37.17 \mathrm{~m}$ [11] [12] [13].

Vertical (gravity) loads acting on the structure are evaluated according to EC0 [14] and EC1 [15] providing as a result a total gravity loading (structural and non-structural) equal to $6.0 \mathrm{kN} / \mathrm{m}^{2}$ and an imposed load of $2.0 \mathrm{kN} / \mathrm{m}^{2}$. The secondary beams are simply supported having a bay width of $2.29 \mathrm{~m}$ oriented along the longitudinal direction of the building. The masses at each floor level according to EC8 [1] for spatial and perimeter frames are found $221 \mathrm{kN}-\mathrm{sec}^{2} / \mathrm{m}$ and 664 $\mathrm{kN}-\sec ^{2} / \mathrm{m}$ respectively, whereas these correspond to $218 \mathrm{kN}-\sec ^{2} / \mathrm{m}$ and 655 $\mathrm{kN}-\mathrm{sec}^{2} / \mathrm{m}$ respectively in the case of ASCE [2]. Based on the provisions of EC3 [16] and EC8, the primary beams are designed for ultimate and serviceability limit states (see Table 1) using steel grade S-275. These primary beams are initially designed for gravity loading and then checked with respect to the seismic loading condition.

Accordingly for the sake of comparison when considering the provisions of AISC/LRFD [17] with AISC/ASCE for the combination of gravity loads (in order to have the same effects on the beams) the same loads are assumed as evaluated according to EC1.

The reference frames are designed according to EC8 with DCH $(q=6.5)$ assuming type $C$ soil stratigraphic profile, important class II ( $\left.\gamma_{I}=1.0\right)$, type 1 elastic response spectrum and $0.25 \mathrm{~g}$ peak ground acceleration. In order to allow an apparent comparison and to have the same seismic intensity an equivalent response spectrum for AISC/ASCE is adopted using importance factor 1.0 and considering soil type $B$ with $S_{s}$ and $S_{1}$ as $1.07 \mathrm{~g}$ and $0.57 \mathrm{~g}$, respectively. Selected soil conditions for both codes and respective geotechnical descriptions [18] are expressed in Table 2. While, the corresponding response spectra for EC8 and ASCE is shown in Figure 2.

According to ASCE a seismic category needs to be assigned for the structure which is found to be in category $D$ (High seismic category) from $S_{D S}(0.713)$ and $S_{D 1}(0.38)$ with the assumed site class. This code limits the use of multi-story

Table 1. Designed primary beams for spatial and perimeter frames.

\begin{tabular}{ccccccc}
\hline & \multicolumn{3}{c}{ EC8/EC3 } & \multicolumn{3}{c}{ ASIC/ASCE } \\
\hline Type of frame & Ductility & Floor & Type of profile & Type & Floor & profile \\
\hline Spatial & High & $1 \sim 9$ & IPE600 & SMF & $1 \sim 9$ & IPE600V \\
& & 1 & IPE600O & & 1 & IPE600O \\
& & $2 \sim 4$ & IPE600V & & $2 \sim 4$ & IPE600V \\
Perimeter & High & 5,6 & IPE600O & SMF & & \\
& & 7 & IPE600 & & $5 \sim 9$ & IPE600 \\
& & & IPE500 & & & \\
\end{tabular}




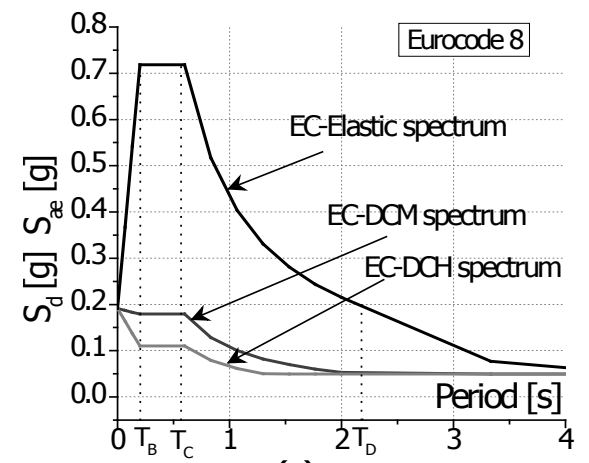

(a)

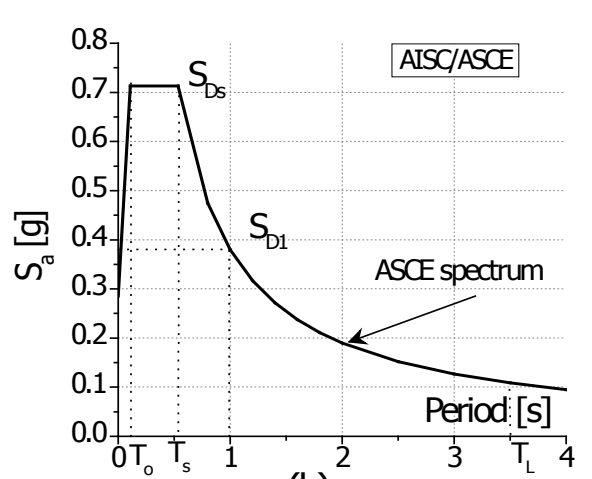

(b)

Figure 2. Response spectra for: EC8 (a) and ASCE (b).

Table 2. Soil Conditions for Design criteria.

\begin{tabular}{|c|c|c|c|}
\hline Building Code & $\begin{array}{l}\text { Code Specified } \\
\text { Soil Type }\end{array}$ & $\begin{array}{l}\text { Code Specified Soil } \\
\text { Description }\end{array}$ & $\begin{array}{l}\text { Geotechnical Description \& } \\
\text { (Unified Soil Classification) }\end{array}$ \\
\hline Eurocode 8 & $\mathrm{C}$ & $\begin{array}{l}\text { Deep deposits of dense } \\
\text { or medium dense and, } \\
\text { gravel or stiff clay with } \\
\text { thickness from several } \\
\text { tens to many hundreds } \\
\text { of metres. }\end{array}$ & $\begin{array}{l}\text { Medium to dense Gravels, silty gravels } \\
\text { and silty-clayey Gravels } \\
\text { (GP,GM,\& GC-GM) or } \\
\text { Medium to dense Sands, silty Sands } \\
\text { and silty-clayey Sands } \\
\text { (SP,SM \& SC-SM) or } \\
\text { Stiff to hard Silts } \\
\text { (ML) or } \\
\text { Stiff to Hard Lean Clays and } \\
\text { silty-Clays (CL \& CL-ML) }\end{array}$ \\
\hline ASCE & B & $\begin{array}{l}\text { Rock with Medium } \\
\text { Strength }\end{array}$ & $\begin{array}{c}\text { Several possibilities, such as Weathered Shale, } \\
\text { Limestone and Sandstone }\end{array}$ \\
\hline
\end{tabular}

IMFs in seismic category $D$ up to $10 \mathrm{~m}$ height therefore the design is carried out considering only $\operatorname{SMF}(R=8)$.

\section{Design Results}

Linear modal dynamic analysis [19] is developed for the seismic design of the frames. It has to be observed that the fundamental period of vibration from the codified formulation is found $1.2 \mathrm{sec}$ which is almost $50 \%$ lower than the modal response spectrum analysis (see Table 3 ). The reduction in the period is due to the fact that simplified formulae given by seismic codes tend to underestimate the fundamental period of vibration, being based on empirical evaluation. The codified formulae globally accounting also for stiffening effects of non-structural elements e.g. partition walls and infills etc. These effects are obviously of major importance for steel frames which exhibits relatively low horizontal stiffness. The underestimation of the natural period (considering only short branch of spectrum) leads to conservative design assumptions e.g. higher design acceleration (consequently high seismic base shear) and in turn larger inter story drifts [10]. 
When using the AISC/ASCE code the fundamental period obtained from the codified formulation is found to be $1.14 \mathrm{sec}$, definitely lower than the one obtained by modal analysis (see Table 4). In this case code specifies scaling factors to be applied for the design forces and drift calculation as shown in Table 4. Design static base shear $\left(V_{d}\right)$ is calculated using ASCE criteria where minimum seismic response coefficient $\left(C_{s}\right)$ is found equal to 0.036 .

The over strength factor $(\Omega)$ is 1.24 for spatial frame; it is 1.13 for perimeter frame. In EC8 $\Omega$ depends on the plastic resistance of beams and on the applied seismic forces. The obtained " $\Omega$ " values from EC8 design are further increased with 1.10 and $\gamma_{o r}$ A minimum value of $\Omega$ is used according to EC8 which are quite smaller than those recommended by AISC/ASCE (as $\Omega_{o}$ is 3).

The obtained columns cross sections using S-355 steel grade of spatial and perimeter frame following EC8/EC3 and AISC/ASCE prescriptions are shown in Table 5. It should be noted that when using EC8 the serviceability limit state condition governs the design. With reference to the AISC/ASCE provisions strength criteria are more stringent, especially due to the fact that the seismic forces are increased by an over strength factor equal to 3. In addition in order to assure the SCWB criteria both codes provide a supplementary check for frame structures which had some influences on the column profiles, this check is normally not satisfied for the top story of the building.

An elastic analysis with DCL $(q=1.5)$ for EC8 and $R=3$ for AISC/ASCE will allows more consistent and lighter design (by avoiding the capacity design criteria and SCWB criteria) but both the codes are not of the opinion to allow the use of this criterion (elastic analysis) for the assumed seismic zone ( $P G A=0.25 \mathrm{~g}$ for EC8 and seismic category $D$ for AISC/ASCE).

In order to allow an assessment between the analyzed frame configurations Figure 3(a) and Figure 3(b) show the "demand" to "capacity ratios" $(D / C)$ of columns strength and $D / C$ ratios of drift for both perimeter and spatial frame configurations designed according to EC8 and AISC/ASCE. Nominally, an optimal design should provide $D / C$ ratios just less than unity; nonetheless this is not possible due to limited number of available profiles and also because these

Table 3. Fundamental period and design base shear following EC8.

\begin{tabular}{ccccc}
\hline Frame & Ductility & Mass $\left[\mathrm{kN}-\sec ^{2} / \mathrm{m}\right]$ & $\mathrm{T}($ modal $)[\mathrm{sec}]$ & $\mathrm{V}_{\mathrm{d}}[\mathrm{kN}]$ \\
\hline Spatial & High & 1989 & 2.4 & 821 \\
Perimeter & High & 5976 & 3.7 & 2346 \\
\hline
\end{tabular}

Table 4. Fundamental period and base shears following AISC/ASCE for SMF

\begin{tabular}{|c|c|c|c|c|c|c|c|}
\hline \multirow{2}{*}{ Frame } & \multirow{2}{*}{$\begin{array}{c}\text { Mass } \\
{\left[\mathrm{kN}-\sec ^{2} / \mathrm{m}\right]}\end{array}$} & \multirow{2}{*}{$\begin{array}{c}\mathrm{T} \text { (modal) } \\
{[\mathrm{sec}]}\end{array}$} & \multirow{2}{*}{$\begin{array}{c}\mathrm{V}_{\mathrm{b}}(\text { modal }) \\
{[\mathrm{kN}]}\end{array}$} & \multirow{2}{*}{$\begin{array}{l}\mathrm{V}_{\text {static }} \\
{[\mathrm{kN}]}\end{array}$} & \multicolumn{2}{|c|}{ Scaling factors } & \multirow{2}{*}{$\begin{array}{c}\mathrm{V}_{\mathrm{d}} \\
{[\mathrm{kN}]}\end{array}$} \\
\hline & & & & & Force & Drift & \\
\hline Spatial & 1962 & 1.9 & 449 & 693 & 1.3 & 1.3 & 584 \\
\hline Perimeter & 5895 & 3.2 & 680 & 2082 & 2.6 & 2.6 & 1768 \\
\hline
\end{tabular}


Table 5. The obtained columns profiles.

\begin{tabular}{|c|c|c|c|c|c|}
\hline \multirow[b]{2}{*}{$\mathrm{Col}$} & \multirow[b]{2}{*}{ Block } & \multicolumn{2}{|c|}{ Perimeter frame } & \multicolumn{2}{|c|}{ Spatial frame } \\
\hline & & AISC/ASCE & EC8 & AISC/ASCE & EC8 \\
\hline \multirow{5}{*}{1} & 1 & $\mathrm{HE} 1000 \mathrm{M}+4$ & HE1000M & HE1000M & HE800M \\
\hline & 2 & HE1000M & HE700B & HE900B & HE650B \\
\hline & 3 & HE1000B & HE550B & HE800B & HE550B \\
\hline & 4 & HE900B & HE500B & HE700B & HE500B \\
\hline & 5 & HE500B & HE450B & HE600B & HE400B \\
\hline \multirow{5}{*}{2} & 1 & $\mathrm{HE} 1000 \mathrm{M}+4$ & HE1000M & $\mathrm{HE} 1000 \mathrm{M}+2$ & $\mathrm{HE} 1000 \mathrm{M}+2$ \\
\hline & 2 & HE1000M & HE700B & HE900B & HE650B \\
\hline & 3 & HE1000B & HE550B & HE800B & HE550B \\
\hline & 4 & HE900B & HE500B & HE700B & HE500B \\
\hline & 5 & HE500B & HE450B & HE600B & HE400B \\
\hline \multirow{5}{*}{3} & 1 & $\mathrm{HE} 1000 \mathrm{M}+4$ & HE1000M & $\mathrm{HE} 1000 \mathrm{M}+2$ & $\mathrm{HE} 1000 \mathrm{M}+2$ \\
\hline & 2 & HE1000M & HE700B & HE900B & HE650B \\
\hline & 3 & HE1000B & HE550B & HE800B & HE550B \\
\hline & 4 & HE900B & HE500B & HE700B & HE500B \\
\hline & 5 & HE500B & HE450B & HE600B & HE400B \\
\hline
\end{tabular}

Note: HE1000M+4 and HE1000M+2 means an additional plate of $4 \mathrm{~cm}$ and $2 \mathrm{~cm}$, respectively, to be welded with flanges of HE1000M.

frames are designed considering five blocks which causes over sizing of the profiles at the next stories. In addition drift criteria and capacity design rules produce over strength of the members reflecting on the $\mathrm{D} / \mathrm{C}$ ratios as well.

For the inter story drifts as per EC8 limit $0.0075 \mathrm{~h}$ (for buildings having ductile non-structural elements) is considered, while according to AISC/ASCE a limit of $0.02 \mathrm{~h}$ is used. The drift criterion is more stringent for perimeter frame in the case of AISC/ASCE as the check is more close to the limit at certain stories. Generally the drift limits are quite far for spatial frames in the case of EC8 proving that drift controls the design in the case of perimeter frame when designed according to AISC/ASCE. Figure 3(c) and Figure 3(d) demonstrates the design requests in term of $\mathrm{D} / \mathrm{C}$ ratios of drift for spatial and perimeter frames designed according to EC8 and AISC/ASCE [20] [21].

\section{Non Linear Analysis}

In order to check the lateral performance of the frames static pushover analysis has been carried out using FEMA-350 [22] recommendations. Triangular distribution (unit load at roof level) of static incremental loads (continues from the gravity load case) has been applied and the displacement at the roof level has been controlled. Mechanical non-linearity of the members has been assumed to 


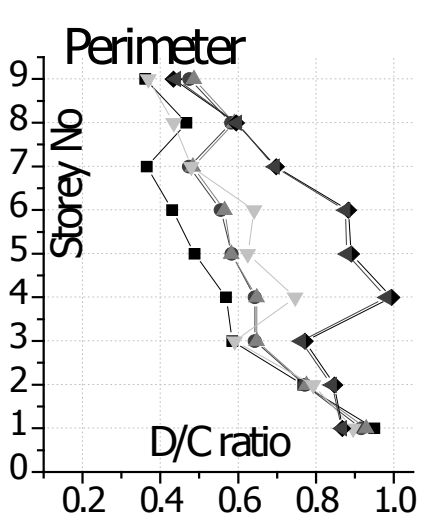

(a)

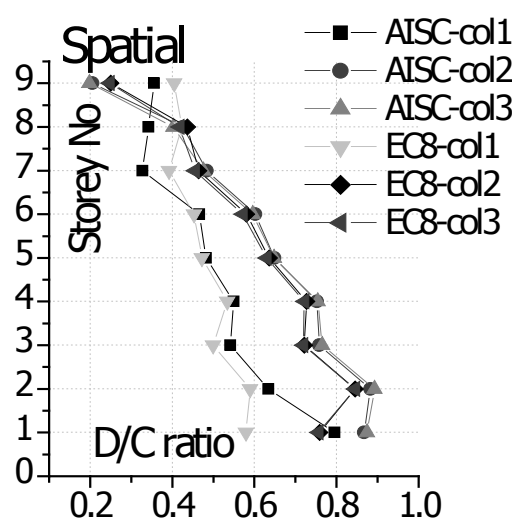

(b)

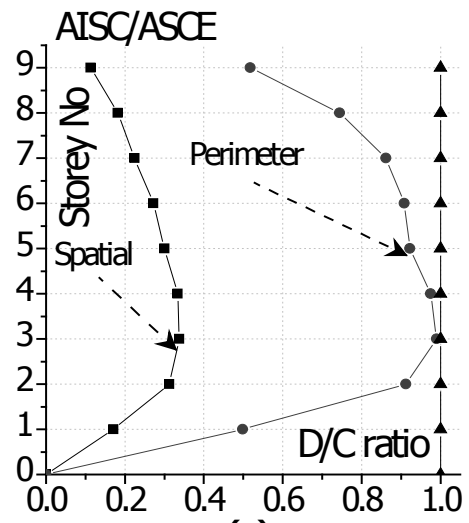

(c)

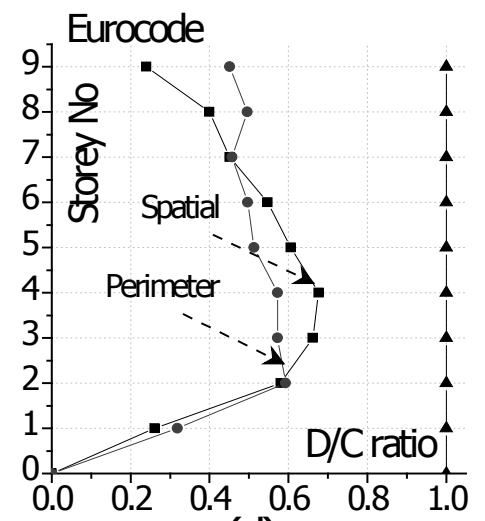

(d)

Figure 3. Design requests according to strength (a) perimeter frames, (b) spatial frames, and drift (c) AISC/ASCE code (d) Eurocode 8.

be concentrated in plastic hinges at the ends of the beams and at the column bases.

The obtained structural capacity curves are plotted in Figure 4(a), Figure 4(b) for all the main analyzed frame configurations in terms of total base shear $\left(V_{b}\right)$ versus top displacement $\left(D_{t}\right)$. In addition in Figure 4(c), Figure 4(d) the ordinate $V_{b}$ is normalized with respect to $V_{y}$ (the lateral load producing the first plastic hinge), and in Figure 5 the ordinate $V_{b}$ is normalized with respect to $V_{d}$ (the design base shear), while the abscissa $D_{t}$ is normalized with $\delta_{1}$ (the lateral displacement corresponding to the first initial yielding). All the relevant values are provided in Table 6 and in Figure 4 and Figure 5, where $V_{u}$ represents the lateral load and $\delta_{u}$ represents the corresponding displacement at failure. From Figure 4(a), Figure 4(b), it is obvious that AISC gives high base shear compared to EC8 as the structure is much stiffer mainly due to the introduction of force and drift scaling factors in the design procedure.

From Figure 4(c), Figure 4(d), it is evidenced that spatial frames are more redundant than perimeter frames. The over strength factors and ductility ratios measured in terms of displacement obtained by the pushover analysis are very high in the case of spatial frames. The high over strength factor in spite of the 


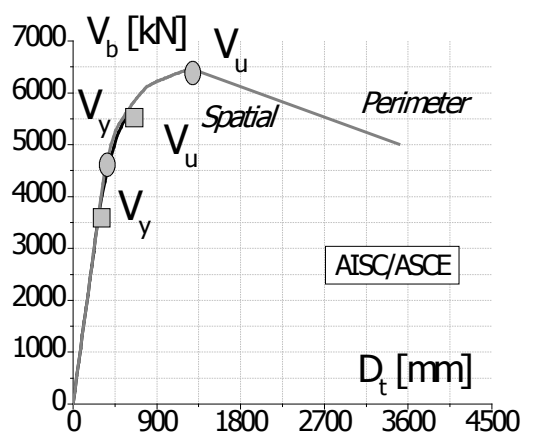

(a)

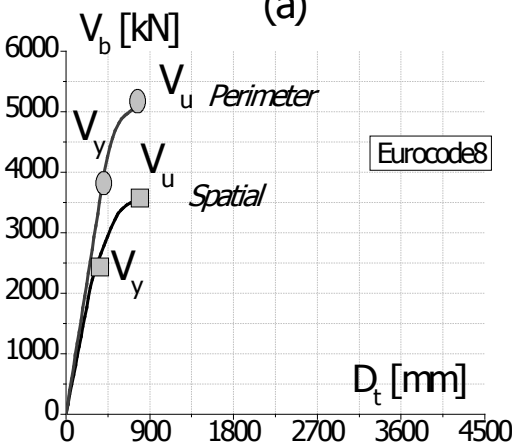

(b)

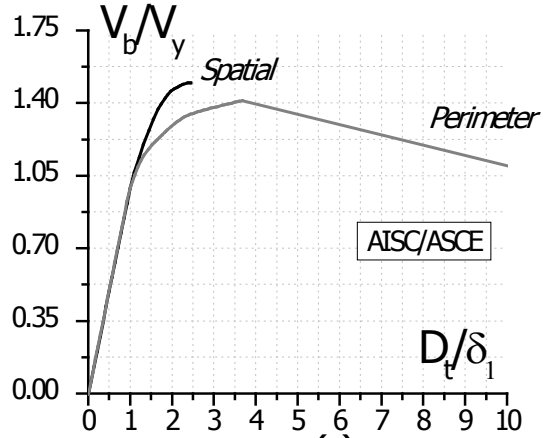

(c)

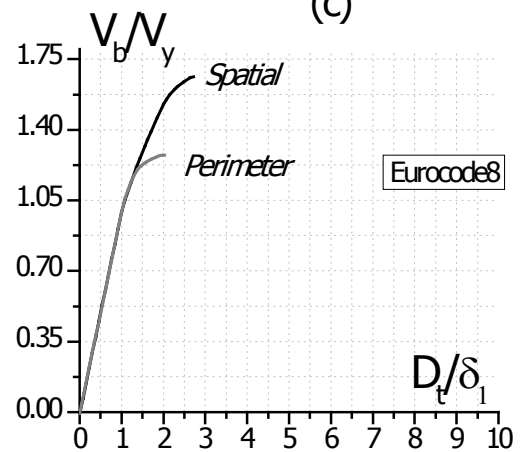

(d)

Figure 4. Pushover curves-9 stories (a) (b) Pushover curves normalized to $V_{y}$ (c) (d).
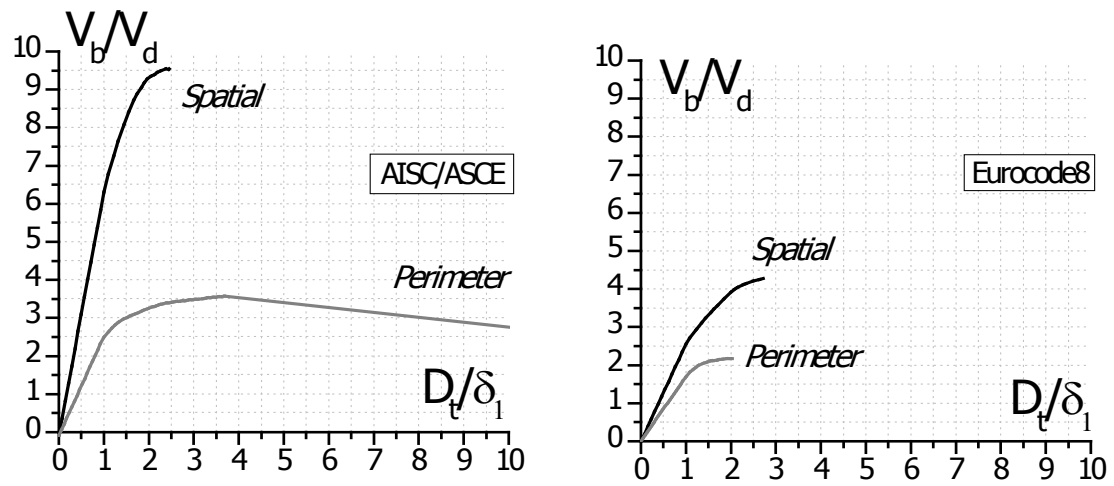

Figure 5. Pushover curves normalized to $\mathrm{V}_{\mathrm{d}}$ for AISC/ASCE-SMF (left) and EC8-DCH (right) frame configurations.

Table 6. Redundancy and over strength factors as per EC8 and AISC.

\begin{tabular}{ccccccccc}
\hline Parameters & $\begin{array}{c}\mathrm{V}_{\mathrm{d}} \\
{[\mathrm{kN}]}\end{array}$ & $\begin{array}{c}\mathrm{V}_{\mathrm{u}} \\
{[\mathrm{kN}]}\end{array}$ & $\begin{array}{c}\mathrm{V}_{\mathrm{y}} \\
{[\mathrm{kN}]}\end{array}$ & $\begin{array}{c}\delta_{\mathrm{u}} \\
{[\mathrm{mm}]}\end{array}$ & $\begin{array}{c}\delta_{1} \\
{[\mathrm{~mm}]}\end{array}$ & $\delta_{\mathrm{u}} / \delta_{1}$ & $\mathrm{~V}_{\mathrm{u}} / \mathrm{V}_{\mathrm{y}}$ & $\mathrm{V}_{\mathrm{u}} / \mathrm{V}_{\mathrm{d}}$ \\
\hline P-EC8 & 2346 & 5101 & 3980 & 831 & 409 & 2.0 & 1.3 & 2.2 \\
S-EC8 & 821 & 3505 & 2100 & 710 & 262 & 2.7 & 1.7 & 4.3 \\
P-AISC & 1768 & 6468 & 4552 & 1272 & 345 & 3.7 & 1.4 & 3.7 \\
S-AISC & 584 & 5622 & 3732 & 689 & 281 & 2.5 & 1.5 & 9.6
\end{tabular}

material over strength factor in both the codes demonstrates the increase of members dimensions due to flexibility of the frames (drift control and period 
control), SCWB criteria and due to high " $D / C$ ratios" of the members.

The abbreviations B, IO, LS, CP, C means basic, immediate occupancy, life safety, collapse prevention and collapse respectively. Figure 6 shows the performance of the analyzed frames when plastic hinges develops. It is evident that perimeter frame designed according to AISC/ASCE gives higher performance than the spatial frame, whereas the spatial frame designed as per EC8 gives comparatively higher performance than the perimeter frame.

All the above aspects are also reflected in the structural weight for the designed profiles, which for the sake of comparison are provided in Figure 7 considering separately the weight of columns $\left(W_{c}\right)$, the weight of beams $\left(W_{b}\right)$ and the total structural weight $\left(W_{t}\right)$. The variation of the weight are presented in the histograms where the overall difference in the weight of beams and columns of the two codes is due to the scaling factors adopted in AISC/ASCE, as the initial period obtained from response spectrum modal analysis was strongly connected by such a factor. As a result, from the analyzed case study it can be highlighted that AISC/ASCE gives costlier basic structural configurations.

\section{Conclusions}

The paper had dealt with the design of spatial and perimeter frames for a 9-storey office building according to the prescription of EC8 and AISC/ASCE. From the present study it is concluded that spatial frames are more redundant than perimeter frames. Furthermore spatial configuration results in higher over
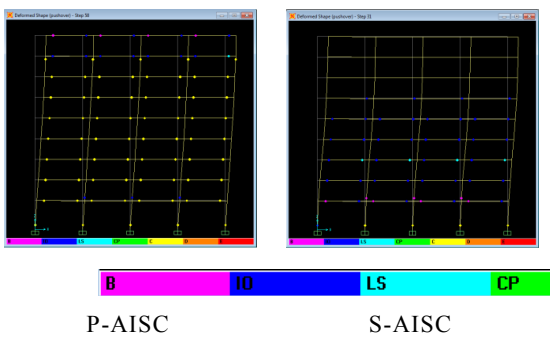

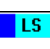

S-AISC

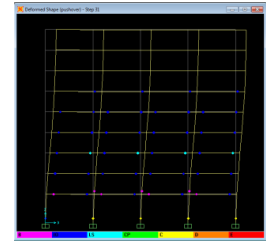

C

P-EC 8

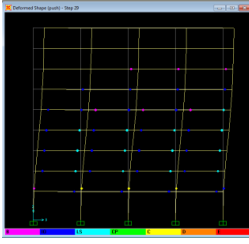

S-EC8

Figure 6. Performance of perimeter and spatial frames.

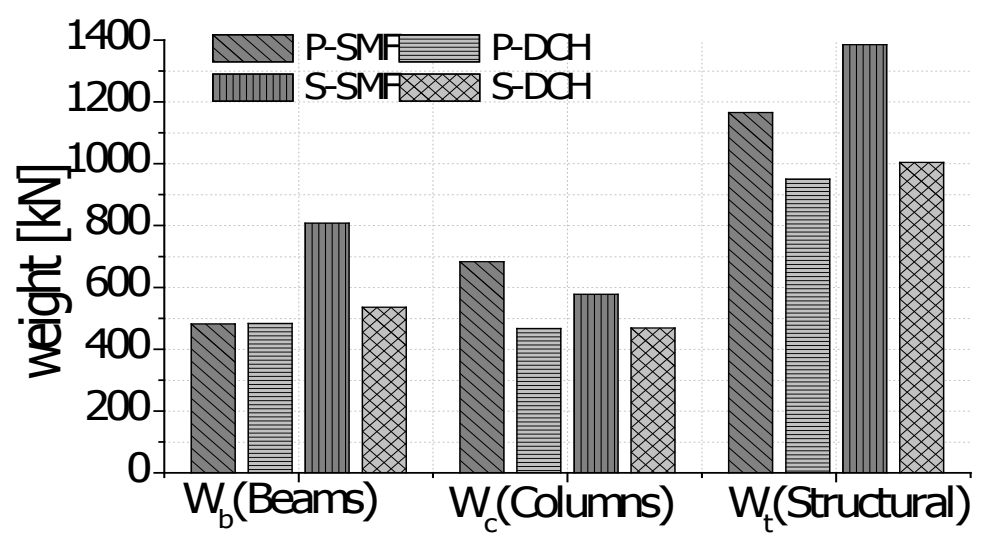

Figure 7. Structural weight for the analyzed frames. 
strength compared to the perimeter framing configuration. The AISC/ASCE gives a stiffer design solution compared to EC 8 which is due to the influence of high $\Omega$ as given by the code. This high $\Omega$ affects the size of the column and consequently the weight of columns. It can be concluded as a whole that the design of moment resisting frames with AISC/ASCE appeared to be more consistent although it resulted in a heavy structural solution compared to the counterpart EC8. The present work is restricted to study the effect of over strength and the behaviour factors only on a limited case. Nevertheless the effect of over strength factor and compatible behaviour factor with the damageability limits need to be focused in the future studies. Such studies are intended to be based on dynamic nonlinear time history analysis.

\section{References}

[1] EN-1998-1 (2005) Eurocode 8, Design of Structures for Earthquake Resistance, Part 1: General Rules, Seismic Actions and Rules for Buildings. European Committee for Standardization, CEN, 36 B-1050, Brussels.

[2] ASCE/SEI-7-10 (2010) Minimum Design Loads for Buildings and Other Structures. 1801 Alexander Bell Drive Reston, Virginia 20191: American Society of Civil Engineers.

[3] FEMA-356 (2000) Commentary for the Seismic Rehabilitation of Buildings, FEMA-356. Federal Emergency Management Agency, Washington DC.

[4] Naqash, M.T., Mahmood, K. and Khoso, S. (2014) An Overview on the Seismic Design of Braced Frames. American Journal of Civil Engineering, 2, 41-47. https://doi.org/10.11648/j.ajce.20140202.15

[5] Uang, C.M. (1991) Establishing R (or Rw) and Cd Factors for Building Seismic Provisions. Journal of Structural Engineering, 117, 19-28. https://doi.org/10.1061/(ASCE)0733-9445(1991)117:1(19)

[6] Rahgozar, M. and Humar, J. (1998) Accounting for Overstrength in Seismic Design of Steel Structures. Canadian Journal of Civil Engineering, 25, 1-15. https://doi.org/10.1139/197-045

[7] Bruneau, M., et al. (1998) Ductile Design of Steel Structures. McGraw-Hill Professional.

[8] Mitchell, D., et al. (2003) Seismic Force Modification Factors for the Proposed 2005 Edition of the National Building Code of Canada. Canadian Journal of Civil Engineering, 30, 308-327. https://doi.org/10.1139/102-111

[9] Naqash, M.T. (2012) Optimum Design of Steel Moment Resisting Frames Using Eurocode 8. Doctorate PhD Thesis, Department of Engineering and Geology (Ph.D. Thesis), University of Chiete and Pescara, Pescara.

[10] Naqash, M.T. (2014) Study on the Fundamental Period of Vibration of Steel Moment Resisting Frames. International Journal of Advanced Structures and Geotechnical Engineering, 3, 1-6.

[11] Naqash, M.T., et al. (2012) Seismic Design of Steel Moment Resisting FramesEuropean versus American Practice. NED University Journal of Research, 9, 45-60.

[12] Naqash, M.T. (2017) Codal Comparisons for the Seismic Resistance of Steel Moment Resisting Frames (MRF). Part A: Codes Approach. International Journal of Construction Engineering and Management, 6, 254-263. 
[13] Naqash, M.T. (2017) Codal Comparisons for the Seismic Resistance of Steel Moment Resisting Frames (MRFs). Part B: Design Approach. International Journal of Construction Engineering and Management, 6, 264-272.

[14] EN-1990 (2002) Eurocode 0, Basis of Structural Design. European Committee for Standardization, CEN, 36 B-1050, Brussels.

[15] EN-1991-1-1 (2004) Eurocode 1, Actions on Structures-Part 1-1: General Actions -Densities, Self-Weight, Imposed Loads for Buildings. European Committee for Standardization, CEN, 36 B-1050, Brussels.

[16] EN-1993-1-1 (2005) Eurocode 3. Design of Steel Structures, Part 1-1: General Rules and Rules for Buildings. European Committee for Standardization, 36 B-1050, Brussels.

[17] ANSI/AISC-360-10 (2010) Specification for Structural Steel Buildings. Illinois 60601-1802, American Institute of Steel Construction, Chicago.

[18] (2017) Standard Practice for Classification of Soils for Engineering Purposes (Unified Soil Classification System).

[19] CSI SAP V15 (2002) Integrated Finite Element Analysis and Design of Structures Basic Analysis Reference Manual. Computers and Structures, Inc., Berkeley.

[20] Naqash, M.T., et al. (2011) European versus American Practice for Seismic Design of Steel Moment Resisting Frames (MRFs). 23rd Italian Steel Conference, Lacco Ameno, 599-610.

[21] Naqash, M.T., et al. (2012) Effects of Capacity Design Rules on Seismic Performance of Steel Moment Resisting Frames. 15 World Conference on Earthquake Engineering, Lisbon.

[22] P. FEMA-350 (2000) Recommended Seismic Design Criteria for New Steel Moment-Frame Buildings FEMA-350. Rich mond, Washington DC. 